70 S. Esperàs, Acla Chem. Scand., 1976, A30, 527-530

71 U. Nagel, K. Pelers, H. G, von Schnering and W. Beck, $f$ Organomet. Chem., 1980, 185, 427-432

72 R. W. Baker and P. Pauling, \%. Chem. Soc. Dalton Trans., $[972,2264-2266$

73 R. Uson, A. Laguna, J. Vicente, J. Garcia, P. G. Jones and G. M. Sheldrick, 7 . Chem. Soc. Dalton Trans., 1981 655-657

74 P. D. Gavens, J. J. Guy, M. J. Mays and G. M. Sheldrick, Acta Crystallogr., 1977, B33, 137-139

74a J. A. J. Jarvis, A. Johnson and R. J. Puddephatt, f. Chem Soc. Chem. Commun., 1973, 373-374

74b I'. G. Jones, A. G, Maddock, M. J. Mays, M. M. Muir and A. F. Williams, 7. Chem. Soc. Dalton Trans., 1977 , 1434-1439

75 P. G. Jones, J. J. Guy and G. M. Sheldrick, Acta Crystallogr, 1976, B32, 3321-3322

76 J. G. Wijnhoven, W. J. P. H. Bosman and P. T. Beurskens, 7. Cryst. Mol. Struct., 1972, 2, 7.15

77 P. B. Hitcheock and P. L. Pye, J. Chem. Soc. Dalton Trans. $1977,1457-1460$

78 N. C. Baenziger, W. E, Bennett and D. M. Soboroff, Acta Crystallogr, 1976, B32, 962-963

79 W. E. Bennett, D. M. Soboroff and N. C. Baenziger, unpublished work, reported in (89)

80 J. J. Guy, P. G. Jones and G. M. Sheldrick, Acta Crystallogr, 1976, B32, 1937-1938

81 J. A. Muir, M. M. Muir and E. Lorca, Acta Crystallogr. $1980, \mathbf{B 3 6}, 931-933$
82 G. C. H. Jones, P. G. Jones, A. G. Maddock, M. J. Mays, I' A. Vergnano and A. F. Williams, \%. Chem. Soc, Dallon Trans., 1977, I440-1443

83 F. W. B. Einstein and R. Restivo, Acta Crystallogr., 1975 B31, 624-626

84 P. G. Jones, G. M. Sheldrick, A. Fügner, F. Götzfried and W. Beck, Chem. Ber, 114, 1413-1417

85 W. Clegg, Acta Crystallogr., 1976, B32, 2712-2714

86 M. Barrow, H. B. Bürgi, D. K. Johnson and L. M. Venanzi, 7. Am. Chem. Soc., 1976, 98, 2356-2357

87 W. Clegg, Acta Crystallogr., 1978, B34, 278-281

88 J. C. Huffmann, R. S. Roth and A. R. Siedle, $\mathscr{7}$. Am. Chem. Soc, $1976,98,4340-4341$

89 N. C. Baenziger, K. M. Dittemore and J. R. Doyle, Inorg Chem., 1974, 13, 805-810

90 J. Strähle and G, Beindorf, private communication G. Beindorf, Diplomarbeit, University of Tübingen, 1978

91 W. Stoeger and A. Rabenau, Z. Naturforsch, 1979, 34b 685-692

92 L. J. Guggenberger, f. Organomet. Chem., 1974, 81, 271-280

93 P. G. Jones, Acta Crystallogr., 1980, B36, 3105-3107

94 T. H. Berg, N. C. Baenziger and J. R. Doyle, $A m$ Crystallogr. Assoc., Series 2, 1978, 6, 15

95 W. Cochran, F. A. Hart and F. G. Mann, f. Chem. Soc., 1957, 2816-2828

96 P. G. Jones, in preparation

97 P. G. Jones, J. Cham. Soc. Chem. Commun., 1980 1031-1033

Part II of this article will be published in the October 1981 issue of Gold Bulletin.

\section{Gold in Bubble Memories}

Bubble memories are microelectronic serial-access information devices in which data from a storage film of garnet are carried as microscopic domains of magnetic polarization in a separate drive layer of garnet grown epitaxially on the storage layer. These domains appear as bubble-like discs when viewed with polarized light. A new type of device, which is currently being developed, utilizes gold films in the movement of information bubbles.

Existing information storage devices, in which magnetic bubbles are carried by travelling potential wells in Permalloy chevron-elements, presently offer a storage density of about 1 million bits $(\mathrm{Mb})$ per square centimetre with a possibility of achieving $1.5 \mathrm{Mb} / \mathrm{cm}^{2}$. This, however, would strain the capabilities of the photo-lithographic technology used in the manufacture of the devices, due to the very high resolution required to produce parts of the circuit pattern which should have dimensions of a fraction of the bubble diameter - for example, sub-micrometre dimensions in the case of a $1 \mu \mathrm{m}$ bubble.

A recent article (IEEE Spectrum, 1981, 18, (2), 30-34) by $S$. Lin and I. L. Saunders, of IBM San Jose Research Laboratory, discusses the possible replacement of the current technology with a new generation of contiguouselement magnetic bubble devices in which the elements are undulating gold deposits. Devices in development at present have a storage density of $4 \mathrm{Mb} / \mathrm{cm}^{2}$, and $16 \mathrm{Mb} / \mathrm{cm}^{2}$ appears within reach with standard production methods.

In the proposed contiguous-disc bubble circuitry, Permalloy propagation patterns are not involved and the bubbles are moved not under the circuit pattern, but alongside it. Thus, lithographic features greater than the bubble diameter are permitted, yielding possible storage densities of $4 \mathrm{Mb} / \mathrm{cm}^{2}$ for $1 \mu \mathrm{m}$ bubbles and $16 \mathrm{Mb} / \mathrm{cm}^{2}$ for $0.5 \mu \mathrm{m}$ bubbles.

In these contiguous-disc devices, the gold circuit pattern acts primarily as a mask for ion implantation to alter the magnetic characteristics of the surface garnet layer. The gold patterns may also carry the currents that provide the magnetic fields for such functions as bubble generation and switching. The flow of magnetization within the garnet, resulting from an applied magnetic field which is forced into the plane of the drive layer as a result of ion implantation of the structure, bends around the gold discs - more accurately diamonds or triangles - like the flow of a river around islands, forming diverging and converging charged walls which attract the memory bubbles and carry them along as the walls rotate with the in-plane magnetic field. This behaviour was depicted by Lin and Saunders in the diagram shown below.

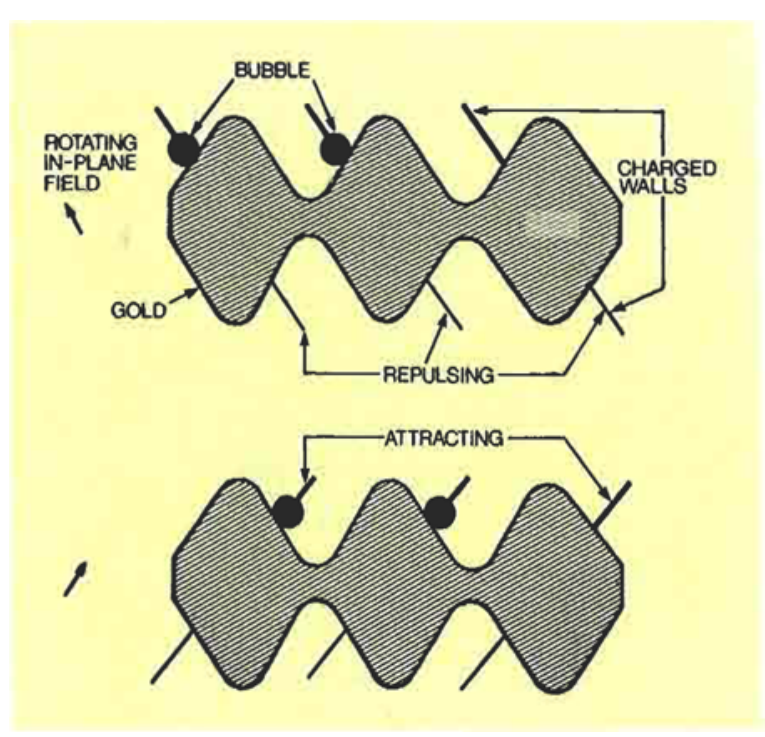

